\title{
Analysis of risk factors for carotid intima-media thickness in patients with type 2 diabetes mellitus in Western China assessed by logistic regression combined with a decision tree model
}

Yuan-Yuan Zhou ${ }^{1,2}$, Hong-Mei Qiu'2 ${ }^{2}$ Ying Yang ${ }^{1 *} \mathbb{D}$ and Yuan-Yuan Han ${ }^{3}$

\begin{abstract}
Background: Cardiovascular disease (CVD) is the leading cause of morbidity and mortality in patients with type 2 diabetes (T2DM). Carotid intima-media thickness (CIMT) is considered a preclinical stage of atherosclerosis. Therefore, it is necessary to identify the related risk factors for CIMT to facilitate the early prevention of CVD. Previous studies have shown that visceral fat area (VFA) is a risk factor for T2DM and CVD. However, few studies have focused on the effects of VFA on CIMT associated with T2DM. Moreover, considering that the body fat distribution shows regional and racial heterogeneity, the purpose of this study was to investigate the predictive value of VFA and other risk factors for CIMT associated with T2DM in Western China.

Methods: In a cross-sectional study, a total of 1372 patients with T2DM were divided into the CIMT (-) group $(n=965)$ and the CIMT $(+)$ group $(n=407)$ based on CIMT values. In addition to the univariate analyses, logistic regression analysis and a decision tree model were simultaneously performed to establish a correlation factor model for CIMT.

Results: Univariate analyses showed that sex, smoking status, age, heart rate, systolic blood pressure (SBP), diastolic blood pressure (DBP), height, weight, body mass index (BMI), waist circumference, hip circumference, waist-hip ratio, VFA, subcutaneous fat area, and the levels of 2-h C-peptide, serum creatinine, urea nitrogen and uric acid were significantly different between the two groups (all $p<0.05$ ). Smoking, increased VFA, female sex and increased BMI were risk factors in the logistic regression analyses $(\mathrm{OR}=5.759, \mathrm{OR}=1.364, \mathrm{OR}=2.239, \mathrm{OR}=1.186$, respectively). In the decision tree model, smoking was the root node, followed by sex, waist circumference, VFA and chronic kidney disease (CKD) in order of importance.
\end{abstract}

Conclusions: In addition to smoking, sex and BMI, VFA has a significant effect on CIMT associated with T2DM in the Chinese Han population in Western China. In addition, the decision tree model could help clinicians make more effective decisions, with its simplicity and intuitiveness, making it worth promoting in future medical research.

\footnotetext{
*Correspondence: yangying2072@126.com

${ }^{1}$ Department of Endocrinology and Metabolism, Fourth Affiliated

Hospital of Kunming Medical University, The Second People's Hospital of Yunnan Province, Kunming 650021, China

Full list of author information is available at the end of the article
}

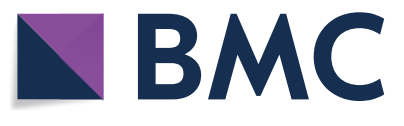

(c) The Author(s) 2020. This article is licensed under a Creative Commons Attribution 4.0 International License, which permits use, sharing, adaptation, distribution and reproduction in any medium or format, as long as you give appropriate credit to the original author(s) and the source, provide a link to the Creative Commons licence, and indicate if changes were made. The images or other third party material in this article are included in the article's Creative Commons licence, unless indicated otherwise in a credit line to the material. If material is not included in the article's Creative Commons licence and your intended use is not permitted by statutory regulation or exceeds the permitted use, you will need to obtain permission directly from the copyright holder. To view a copy of this licence, visit http://creativeco mmons.org/licenses/by/4.0/. The Creative Commons Public Domain Dedication waiver (http://creativecommons.org/publicdomain/ zero/1.0/) applies to the data made available in this article, unless otherwise stated in a credit line to the data. 
Trial registration ChiCTR, ChiCTR1900027739. Registered 24 November 2019-Retrospectively registered, http://www. chictr.org.cn/index.aspx.

Keywords: Type 2 diabetes, Carotid intima-media thickness, Visceral fat area, Decision tree

\section{Background}

With continuous improvements in living standards, type 2 diabetes (T2DM) has become a serious threat to human health. According to International Diabetes Federation (IDF) statistics, in 2011, the global number of patients with T2DM reached 366 million people, of whom $80 \%$ are in developing countries. It is estimated that there will be nearly 552 million T2DM patients worldwide by 2030 [1]. The risk of cardiovascular disease (CVD) in patients with T2DM is $2-3$ times higher than that in non-T2DM patients [2]. CVD is the leading cause of morbidity and mortality in patients with T2DM worldwide [3]. Therefore, it is very strategically important to prevent and treat diabetic macrovascular disease.

Cardiovascular disease (CVD) is a general term for heart and vascular diseases, such as acute coronary syndrome, myocardial infarction, stroke, and peripheral artery diseases [4-6]. Atherosclerosis is the underlying cause of most CVD [7]. More importantly, increased carotid intima-media thickness is considered as an early deterioration in the arterial intima and is a preclinical stage of atherosclerosis $[8,9]$. Despite controversial results, the majority of studies have recommended measuring CIMT in clinical practice for the assessment of cardiovascular risk [10-15]. Therefore, it is necessary to identify the relevant risk factors for CIMT to facilitate the early comprehensive prevention and treatment of macroangiopathy. According to previous studies, CIMT can be affected by many factors, including age [16-18], sex [16-18], smoking [19, 20], blood pressure [21], blood lipid levels [22], thyroid function [23, 24], blood glucose levels [25], blood glucose level fluctuations, and C-peptide levels $[26,27]$.

Recently, research regarding the effects of fat metabolism on CVD has become a challenging topic globally. Recently, the International Atherosclerosis Society and the International Chair on Cardiometabolic Risk Working Group on Visceral Obesity jointly released a statement in "The Lancet: Diabetes \& Endocrinology" to the effect that visceral fat is a risk factor for T2DM, atherosclerosis and CVD [28]. However, few studies have focused on the effect of visceral fat area (VFA) on CIMT in patients with T2DM.

In view of the regional and ethnic differences that might impact the distribution of body fat in individuals, our study focused on populations in Western China. The purpose of our study was to investigate the impacts of
VFA and other traditional risk factors on CIMT among patients with T2DM. Furthermore, to make the results more reliable, logistic regression analysis and a decision tree model were simultaneously applied.

\section{Methods \\ Subjects}

This is a cross-sectional study in which patients with T2DM were recruited from March 2018 to August 2019 in the Department of Endocrinology, the Sixth Affiliated Hospital of Kunming Medical University, Yuxi City, Yunnan Province, China, and the Clinical Medicine Subcenter for National Standardized Metabolic Disease Management Center (MMC). The inclusionwere the diagnostic criteria for T2DM established by the American Diabetes Association (ADA) [29].

The exclusion criteria were as follows: (1) acute complications of diabetes mellitus; (2) malignant tumor; (3) severe liver dysfunction; (4) estimated glomerular filtration rate $(\mathrm{eGFR})<30 \mathrm{~mL} / \mathrm{min}$; (5) acute and chronic infectious diseases; (6) positive islet autoantibodies; (7) age $\geq 85$ years and age $<18$ years; (8) pregnancy; and (9) a history of angina, myocardial infarction, heart failure, abdominal aortic aneurysm, stroke and other cardiovascular diseases or typical clinical manifestations, electrocardiograms and other imaging evidence supporting the diagnosis of these diseases. Finally, a total of 1372 patients with T2DM were included.

\section{Ethical principles}

This study was conducted in line with the principles set out in the Helsinki Declaration and approved by the Ethics Committee of the Sixth Affiliated Hospital of Kunming Medical University (No. 201934). Written informed consent was obtained from all subjects.

\section{Clinical information collection}

The basic clinical information of the patient was recorded in detail, including sex, age, and smoking status. Height and weight were measured in the standing position. Waist circumference was measured at the horizontal plane midway between the lowest rib and the iliac crest. Hip circumference was measured at the widest part of the buttocks, and the waist-hip ratio (WHR) was calculated. Body mass index (BMI) was calculated as the weight $(\mathrm{kg})$ divided by the square of the height $\left(\mathrm{m}^{2}\right)$. After sitting quietly for 5-10 $\mathrm{min}$, heart rate was monitored. Systolic 
blood pressure (SBP) and diastolic blood pressure (DBP) of the bilateral upper arm were measured twice with a standard cuff mercury sphygmomanometer. The mean values of SBP and DBP were recorded.

\section{Laboratory examination}

All the subjects avoided high-fat food and alcohol 1 day before blood collection. Venous blood was collected the next day on an empty stomach to assess the levels of fasting blood glucose (Glu0), fasting serum C-peptide (C0), fasting serum insulin (Ins0), glycated hemoglobin A1c (HbA1c), triglyceride (TG), cholesterol (TC), high-density lipoprotein cholesterol (HDL-c), low-density lipoprotein cholesterol (LDL-c), serum creatinine (Scr), blood urea nitrogen $(\mathrm{BUN})$, and uric acid (UA). The estimated glomerular filtration rate (eGFR) was calculated according to the "Chinese-abbreviated Modification of Diet in Renal Disease (c-aMDRD)" [30-32]. Thereafter, all subjects underwent an oral glucose tolerance test (OGTT) to subsequently measure the 2-h postprandial blood glucose (Glu120), 2-h postprandial serum C-peptide (C120) and 2-h postprandial serum insulin (Ins120) levels.

The eGFR was calculated as follows: eGFR $(\mathrm{mL} / \mathrm{min} /$ $\left.1.73 \mathrm{~m}^{2}\right)=175 \times \mathrm{Scr}^{-1.234} \times \operatorname{age}^{-0.179} \times(0.79$ if female $)$ (note that the unit of Scr in the formula is $\mathrm{mg} / \mathrm{dl}$ ).

\section{Measurement of common carotid intima-media thickness}

All subjects were supine and the anterior neck was fully exposed with the head back and inclined to the side away from the ultrasound physician while taking care to avoid muscle tension caused by overextension of the neck. A high-resolution color ultrasound system (iE33, Philips, USA) was used to measure the common carotid intima thickness at the far wall of the bilateral common carotid arteries approximately $1 \mathrm{~cm}$ proximal to the carotid bifurcation. Both the left CIMT (L-CIMT) and right CIMT (R-CIMT) were recorded. Measurements of CIMT were performed by experienced ultrasound physicians.

\section{Measurement of visceral fat area and subcutaneous fat area}

The VFA and subcutaneous fat area (SFA) of the subjects in the supine position were determined with a visceral fat analyzer (HDS-2000, Omron, China) using the bioelectrical impedance method. Measurements of VFA and SFA were performed by physicians in the MMC.

\section{Calculation of the ankle brachial index}

All subjects were supine, with arms and legs at the same level as the heart, for a minimum of $10 \mathrm{~min}$ before measurement. A blood pressure monitor (BP-203RPE III, Omron, China) was employed to measure the ankle artery pressure and brachial artery pressure. The ankle brachial index (ABI) was calculated as the ankle artery pressure divided by the brachial artery pressure. Both the left $\mathrm{ABI}(\mathrm{L}-\mathrm{ABI})$ and right CIMT (R-ABI) were recorded. Measurements of $\mathrm{ABI}$ were performed by physicians in the MMC.

\section{Definitions}

Based on the "Chinese Guidelines for the Prevention and Treatment of Hypertension" [33] in treated or untreated subjects, $\mathrm{SBP} \geq 140 \mathrm{mmHg}$ and/or $\mathrm{DBP} \geq 90 \mathrm{mmHg}$ is defined as hypertension.

Based on the "Expert Consensus on Integrated Management of Type 2 Diabetes and Obesity in China" [34], a $B M I \geq 24 \mathrm{~kg} / \mathrm{m}^{2}$ was defined as overweight, and a $\mathrm{BMI} \geq 28 \mathrm{~kg} / \mathrm{m}^{2}$ was defined as obesity. In addition, abdominal obesity was defined as a waist circumference $\geq 90 \mathrm{~cm}$ in male or $\geq 80 \mathrm{~cm}$ in female participants.

Based on the "Guidelines for vascular ultrasonography" [35], CIMT $\geq 1.0 \mathrm{~mm}$ was defined as increased CIMT.

Based on the "Guidelines for the Prevention and Treatment of Type 2 Diabetes in China" [36], VFA $\geq 80 \mathrm{~cm}^{2}$ was defined as increased VFA; $A B I \leq 0.9$ was defined as stenosis, and $\mathrm{ABI}>0.9$ was defined as nonstenosis; Glu $0<4.4 \mathrm{mmol} / \mathrm{L}$ was defined as excessively controlled, $4.4 \mathrm{mmol} / \mathrm{L} \leq \mathrm{Glu} 0 \leq 7.0 \mathrm{mmol} / \mathrm{L}$ was defined as well controlled, and Glu0 $>7.0 \mathrm{mmol} / \mathrm{L}$ was defined as poorly controlled; Glu $120 \leq 7.8 \mathrm{mmol} / \mathrm{L}$ was defined as well controlled, $7.8 \mathrm{mmol} / \mathrm{L}<\mathrm{Glu} 120<10 \mathrm{mmol} / \mathrm{L}$ was defined as generally controlled, and Glu120 $\geq 10 \mathrm{mmol} / \mathrm{L}$ was defined as poorly controlled; and $\mathrm{HbA1c}<7 \%$ was defined as well controlled, $7 \% \leq \mathrm{HbA} 1 \mathrm{c}<8 \%$ was defined as generally controlled, and $\mathrm{HbA} 1 \mathrm{c} \geq 8 \%$ was defined as poorly controlled. The threshold for SFA in the Chinese population has not been clearly defined; therefore, we defined SFA $\geq 100 \mathrm{~cm}^{2}$ as "increased SFA" based on a previous study [37].

Based on the "Chinese Guidelines on Prevention and Treatment of Dyslipidemia in Adults" [38], meeting any of the following criteria was defined as dyslipidemia: $\mathrm{TC} \geq 6.22 \mathrm{mmol} / \mathrm{L} ; \mathrm{TG} \geq 2.26 \mathrm{mmol} / \mathrm{L}$; or LDL-c $\geq 4.14 \mathrm{mmol} / \mathrm{L}$.

Based on "Kidney Disease Improving Global Outcomes (KDIGO)" [39, 40]: eGFR $\geq 90 \mathrm{~mL} / \mathrm{min}$ was defined as GFR category 1 (G1), $60 \mathrm{~mL} / \mathrm{min} \leq \mathrm{eGFR}<90 \mathrm{~mL} /$ min was defined as GFR category 2 (G2), and $30 \mathrm{~mL} /$ $\min \leq \mathrm{eGFR}<60 \mathrm{~mL} / \mathrm{min}$ was defined as GFR category 3 (G3).

Based on the "Chinese Multidisciplinary Expert Consensus on the Diagnosis and Treatment of Hyperuricemia and Related Diseases" [41], hyperuricemia (HUA) was defined as a fasting serum UA $>420 \mu \mathrm{mol} / \mathrm{L}$ in male subjects and $>360 \mu \mathrm{mol} / \mathrm{L}$ in female subjects. 


\section{Statistical analysis}

Continuous variables are presented as the mean \pm standard deviation (SD), and categorical variables are presented as percentages (shown in Table 1). On the basis of the CIMT values, subjects were divided into two groups: CIMT $<1.0 \mathrm{~mm}$ [CIMT $(-)$ group, $\mathrm{n}=965]$ and CIMT $\geq 1.0 \mathrm{~mm}$ [CIMT $(+)$ group, $\mathrm{n}=407$ ]. Differences between the two groups were assessed. The continuous variables with normal distributions were analyzed by Welch's $t$ test, and variables with skewed distributions

Table 1 Clinical baseline characteristics of patients with type 2 diabetes

\begin{tabular}{|c|c|c|c|c|}
\hline Variable & $\begin{array}{l}\text { Total } \\
\mathrm{N}=1372\end{array}$ & $\begin{array}{l}\text { CIMT(-) group } \\
\mathrm{N}=965\end{array}$ & $\begin{array}{l}\text { CIMT(+) group } \\
\mathrm{N}=407\end{array}$ & $P$ \\
\hline Gender (male/female) & $843 / 529(61.4 \%, 38.6 \%)$ & $558 / 407(57.8 \%, 42.2 \%)$ & $285 / 122(70 \%, 30 \%)$ & $0.000^{\mathrm{a} * *}$ \\
\hline Smoking (no/yes) & $809 / 563(59.0 \%, 41.0 \%)$ & $654 / 311(67.8 \%, 32.2 \%)$ & 155/252 (38.1\%, 61.9\%) & $0.000^{\mathrm{a} * *}$ \\
\hline Age (years) & $53.66 \pm 11.44$ & $53.04 \pm 11.49$ & $55.12 \pm 11.20$ & $0.001^{b * *}$ \\
\hline Heart rate (beat/min) & $75.51 \pm 10.86$ & $75.85 \pm 10.94$ & $74.70 \pm 10.64$ & $0.042^{\mathrm{b} *}$ \\
\hline $\mathrm{SBP}(\mathrm{mm} / \mathrm{Hg})$ & $126.42 \pm 16.28$ & $125.37 \pm 16.07$ & $128.90 \pm 16.51$ & $0.000^{\mathrm{b} * *}$ \\
\hline $\mathrm{DBP}(\mathrm{mm} / \mathrm{Hg})$ & $76.52 \pm 9.86$ & $76.05 \pm 9.70$ & $77.64 \pm 10.16$ & $0.005^{b * *}$ \\
\hline Height (cm) & $161.77 \pm 9.25$ & $161.42 \pm 9.15$ & $162.60 \pm 9.44$ & $0.013^{\mathrm{b} *}$ \\
\hline Weight (kg) & $67.09 \pm 12.64$ & $66.15 \pm 12.40$ & $69.32 \pm 12.94$ & $0.000^{\mathrm{b} * *}$ \\
\hline $\mathrm{BMI}\left(\mathrm{kg} / \mathrm{m}^{2}\right)$ & $25.42 \pm 3.60$ & $25.19 \pm 3.57$ & $25.98 \pm 3.61$ & $0.000^{\mathrm{b} * *}$ \\
\hline Waist circumference (cm) & $88.74 \pm 9.29$ & $87.99 \pm 9.22$ & $90.50 \pm 9.22$ & $0.000^{\mathrm{b} * *}$ \\
\hline Hip circumference (cm) & $96.30 \pm 7.21$ & $95.95 \pm 7.27$ & $97.12 \pm 7.01$ & $0.004^{\mathrm{b} * *}$ \\
\hline WHR & $0.921 \pm 0.07$ & $0.92 \pm 0.08$ & $0.93 \pm 0.07$ & $0.006^{\mathrm{b} * *}$ \\
\hline VFA $\left(\mathrm{cm}^{2}\right)$ & $86.34 \pm 39.82$ & $82.54 \pm 38.23$ & $95.34 \pm 42.05$ & $0.000^{\mathrm{b} * *}$ \\
\hline $\mathrm{SFA}\left(\mathrm{cm}^{2}\right)$ & $172.54 \pm 60.80$ & $168.42 \pm 60.26$ & $182.33 \pm 61.01$ & $0.000^{\mathrm{b} * *}$ \\
\hline Glu0 (mmol/L) & $9.55 \pm 3.57$ & $9.58 \pm 3.76$ & $9.46 \pm 3.08$ & $0.678^{b}$ \\
\hline Glu120 (mmol/L) & $14.84 \pm 4.98$ & $14.69 \pm 4.94$ & $15.20 \pm 5.05$ & $0.056^{b}$ \\
\hline Ins0 ( $\mu \mid U / m L)$ & $9.31 \pm 5.90$ & $9.21 \pm 5.94$ & $9.56 \pm 5.80$ & $0.316^{b}$ \\
\hline $\operatorname{lns} 120(\mu \mid \mathrm{U} / \mathrm{mL})$ & $24.03 \pm 18.78$ & $23.76 \pm 18.93$ & $24.67 \pm 18.42$ & $0.258^{b}$ \\
\hline $\mathrm{CO}(\mu \mathrm{g} / \mathrm{L})$ & $1.48 \pm 1.18$ & $1.45 \pm 1.19$ & $1.55 \pm 1.17$ & $0.126^{b}$ \\
\hline $\mathrm{C} 120(\mu \mathrm{g} / \mathrm{L})$ & $3.41 \pm 9.23$ & $3.40 \pm 10.61$ & $3.43 \pm 4.46$ & $0.023^{b *}$ \\
\hline $\mathrm{HbA} 1 \mathrm{C}(\%)$ & $9.28 \pm 2.39$ & $9.23 \pm 2.42$ & $9.39 \pm 2.33$ & $0.280^{b}$ \\
\hline eGFR (mL/min/1.73m²) & $137.05 \pm 112.14$ & $135.57 \pm 67.83$ & $140.57 \pm 177.56$ & $0.015^{\mathrm{b} *}$ \\
\hline BUN (mmol/L) & $5.346 \pm 10.84$ & $5.41 \pm 12.80$ & $5.21 \pm 2.73$ & $0.002^{\mathrm{b} * *}$ \\
\hline $\operatorname{Scr}(\mu \mathrm{mol} / \mathrm{L})$ & $64.18 \pm 20.69$ & $63.18 \pm 20.06$ & $66.54 \pm 21.95$ & $0.002^{\mathrm{b} * *}$ \\
\hline $\mathrm{UA}(\mu \mathrm{mol} / \mathrm{L})$ & $332.75 \pm 95.49$ & $329.98 \pm 95.37$ & $339.31 \pm 95.57$ & $0.022^{\mathrm{b} * *}$ \\
\hline $\mathrm{TG}(\mathrm{mmol} / \mathrm{L})$ & $2.72 \pm 2.51$ & $2.81 \pm 2.66$ & $2.53 \pm 2.10$ & $0.436^{b}$ \\
\hline $\mathrm{TC}(\mathrm{mmol} / \mathrm{L})$ & $4.61 \pm 1.33$ & $4.64 \pm 1.35$ & $4.54 \pm 1.28$ & $0.166^{\mathrm{b}}$ \\
\hline $\mathrm{HDL}-\mathrm{c}(\mathrm{mmol} / \mathrm{L})$ & $1.34 \pm 4.29$ & $1.40 \pm 5.11$ & $1.19 \pm 0.40$ & $0.006^{b * *}$ \\
\hline LDL-c (mmol/L) & $2.30 \pm 0.90$ & $2.29 \pm 0.90$ & $2.34 \pm 0.88$ & $0.497^{b}$ \\
\hline L-CIMT (mm) & $1.49 \pm 1.83$ & $0.73 \pm 0.13$ & $3.29 \pm 2.57$ & $0.000^{\mathrm{b} * *}$ \\
\hline R-CIMT (mm) & $1.48 \pm 1.83$ & $0.72 \pm 0.13$ & $3.26 \pm 2.71$ & $0.000^{\mathrm{b} * *}$ \\
\hline Mean value of CIMT (mm) & $1.48 \pm 1.84$ & $0.73 \pm 0.13$ & $3.27 \pm 2.62$ & $0.000^{\mathrm{b} * *}$ \\
\hline$L-A B \mid$ & $1.14 \pm 0.09$ & $1.14 \pm 0.08$ & $1.15 \pm 0.09$ & $0.057^{b}$ \\
\hline$R-A B \mid$ & $1.14 \pm 0.09$ & $1.14 \pm 0.08$ & $1.15 \pm 0.09$ & $0.051^{b}$ \\
\hline Mean value of $A B I$ & $1.14 \pm 0.08$ & $1.14 \pm 0.08$ & $1.15 \pm 0.08$ & $0.055^{b}$ \\
\hline
\end{tabular}

SBP systolic blood pressure, DBP diastolic blood pressure, BMI body mass index, WHR waist hip ratio, VFA visceral fat area, SFA subcutaneous fat area, GluO fasting blood glucose, Glu120 2-hour postprandial blood glucose, InsO fasting serum insulin, Ins 120 2-hour postprandial serum insulin, CO fasting serum C peptide, C120 2-hour postprandial serum C-peptide, HbA1C glycated hemoglobin A1c, eGFR estimated glomerular filtration rate, BUN blood urea nitrogen, Scr serum creatinine, UA uric acid, TG triglyceride, TC cholesterol, HDL-c high density lipoprotein cholesterol, LDL-c low density lipoprotein cholesterol, CIMT carotid intima media thickness, L-CIMT left carotid intima media thickness, $R$-CIMT right carotid intima media thickness, $A B l$ ankle brachial index, $L-A B /$ left ankle brachial index, $R$ - $A B \mid$ right ankle brachial index

a Chi-square test

${ }^{b}$ Mann-Whitney's $U$ test

${ }^{*} P<0.05,{ }^{* *} P<0.01$ 
were analyzed by the Mann-Whitney $U$ test. For categorical variables, the Chi square test was used. The correlations of VFA with BMI, waist circumference and SFA were analyzed by Pearson correlation analysis. Both logistic regression analysis and decision tree modeling were performed to establish a correlation factor model for CIMT in patients with T2DM. The methods for the logistic regression were based on forward selection (likelihood ratio), with $p<0.05$ as the entry criterion and $p>0.1$ as the removal criterion. The decision tree method was based on the Chi squared automatic interaction detector (CHAID). Seventy percent of the subjects were set as the training dataset to build the model, and the remaining thirty percent were set as the test dataset to verify the model.

Variable assignments were used in the logistic regression and decision tree modeling. $p<0.05$ was considered an indicator of a significant difference. All analyses were evaluated with SPSS version 20.0 (SPSS 20.0, IBM, USA). A power analysis was conducted with PASS 19.0 to calculate the number of subjects needed in this study; PASS (https://www.ncss.com/software/pass) is a professional software used to calculate sample size [42]. We found that the incidence of increased CIMT in patients with T2DM was $23.5 \%$ in a study conducted in a Chinese population [27]. Based on these data, a sample size of 1291 was needed. Thus, the inclusion of 1372 patients in this study is reasonable and provides sufficient statistical power. The calculation result is showed in the Additional file 1.

The quality of the studies was evaluated using the Strengthening the Reporting of Observational Studies in Epidemiology (STROBE) checklist (https://www.strob e-statement.org/index.php?id=available-checklists). The STROBE checklist is shown in the Additional file 2.

\section{Results}

\section{Clinical baseline characteristics}

A total of 1372 patients with T2DM were finally enrolled in the study (61.4\% male and $38.6 \%$ female; mean age: $53.66 \pm 11.44$ years). On the basis of CIMT values, the subjects were divided into the CIMT $<1.0 \mathrm{~mm}$ group [CIMT $(-), \mathrm{n}=965$ ] and the CIMT $\geq 1.0 \mathrm{~mm}$ group [CIMT $(+), \mathrm{n}=407]$. Table 1 summarizes the clinical baseline characteristics of the participants in the two groups (Additional file 3).

\section{Univariate analysis of possible risk factors for CIMT in patients with T2DM}

Univariate analyses showed that the age, height, weight, BMI, waist circumference, hip circumference, WHR, SBP, DBP, VFA, SFA, C120, Scr, and UA in the CIMT $(+)$ group were significantly higher than those in the CIMT
$(-)$ group (all $p<0.05)$. In addition, sex, smoking status, heart rate and BUN were significantly different between the two groups (all $p<0.05$ ). Other factors, including Glu0, Glu120, Ins0, Ins120, C0, HbA1c, TG, TC, LDL, $\mathrm{L}-\mathrm{ABI}, \mathrm{R}-\mathrm{ABI}$, and the mean value of $\mathrm{ABI}$ were not significantly different between the two groups (all $p>0.05$ ). These results are shown in Table 1.

\section{Correlation analysis of VFA with BMI, waist circumference and SFA}

BMI, waist circumference and SFA are commonly used in the clinical evaluation of body fat distribution. In the present study, a correlation analysis between VFA and these indicators was conducted. The Pearson correlation coefficients $r$ of VFA with BMI, waist circumference and SFA were $0.781,0.787$, and 0.763 , respectively. The results are depicted in Table 2 and Fig. 1.

\section{Logistic regression analysis of factors associated with CIMT in patients with T2DM}

The variable assignments used in the logistic regression are shown in Table 3. The relevant factors that were ultimately included in the logistic regression model were smoking, sex, VFA and BMI (shown in Table 4). The results showed that the risk of CIMT was 5.759 times higher in smokers than in nonsmokers (odds ratio $(\mathrm{OR})=5.759$, 95\% confidence interval $(\mathrm{CI})(3.884,8.541)$ ). Patients with VFA $\geq 80 \mathrm{~cm}^{2}$ had a 1.364-fold higher risk of CIMT compared with those with VFA $<80 \mathrm{~cm}^{2}$ $(\mathrm{OR}=1.364,95 \% \mathrm{CI}(1.018,1.828))$. Compared to male patients, female patients had a 2.239-fold higher risk of CIMT $(\mathrm{OR}=2.239,95 \% \mathrm{CI}(1.486,3.733))$. The larger the $\mathrm{BMI}$ value was, the higher the risk of CIMT $(\mathrm{OR}=1.186$, $95 \%$ CI $(1.017,1.384))$.

\section{Decision tree modeling of factors associated with CIMT in patients with T2DM}

The variables included in the decision tree model are shown in Table 3; these were the same variables as those used in the logistic regression analysis. In the present study, $70 \%$ of the subjects were randomly set as a training

Table 2 Correlations of VFA with BMI, waist circumference and SFA

\begin{tabular}{llll}
\hline & BMI & $\begin{array}{l}\text { Waist } \\
\text { circumference }\end{array}$ & SFA \\
\hline VFA & & & \\
Pearson correlation & $0.781^{* *}$ & $0.787^{* *}$ & $0.763^{* *}$ \\
$P$ (2-tailed) & 0.000 & 0.000 & 0.000 \\
\hline
\end{tabular}

VFA visceral fat area, $B M I$ body mass index, SFA subcutaneous fat area

${ }^{* *}$ Correlation is significant at the 0.01 level (2-tailed) 

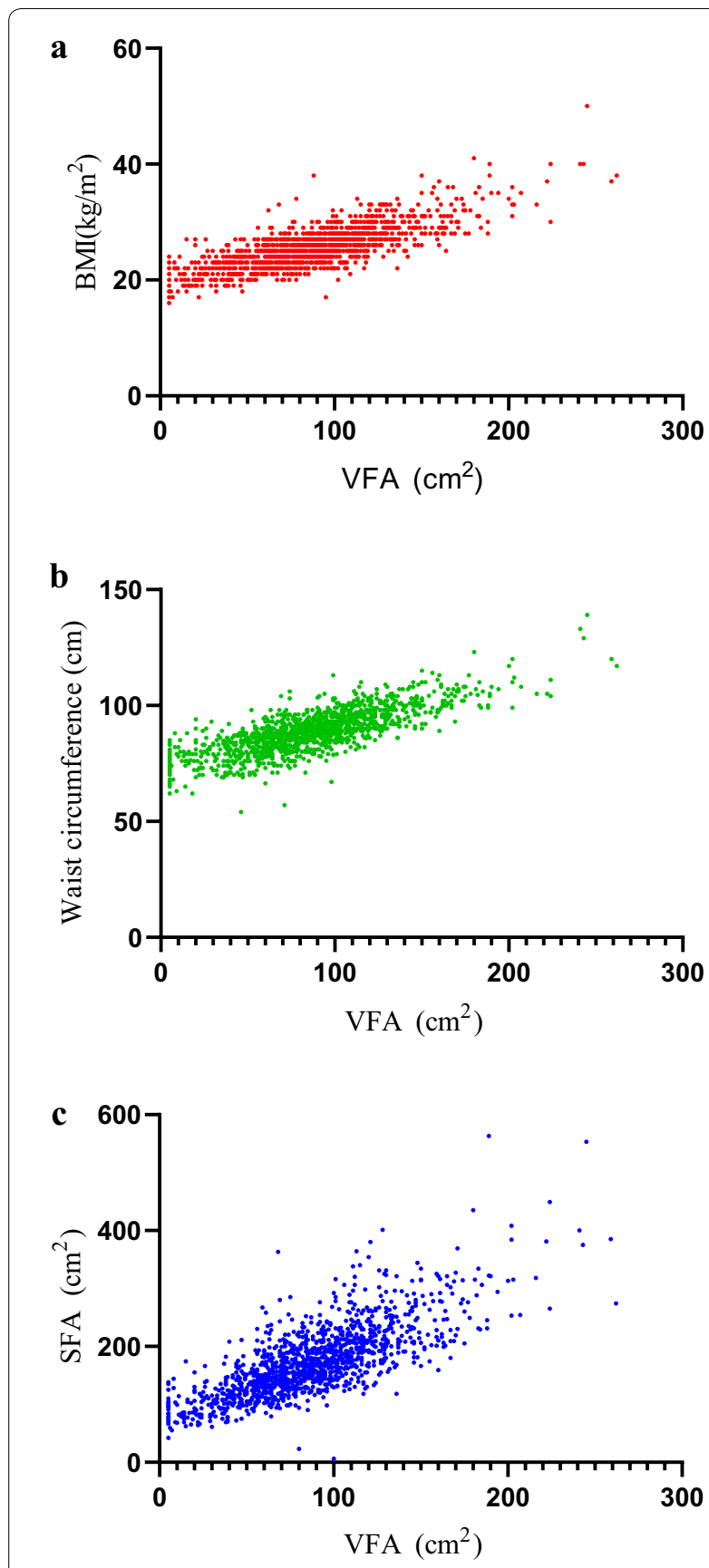

Fig. 1 Correlations of VFA with BMI (a), Waist circumference (b) and SFA (c). VFA visceral fat area, BMI body mass index, SFA subcutaneous fat area

dataset $(n=985)$ to build the model, and the remaining $30 \%$ were set as a test dataset $(n=387)$ to verify the model. As described in Fig. 2, smoking was the first variable or root node in this decision tree model, followed by sex, waist circumference, VFA and CKD in order of their importance in the study decision tree. Table 5 summarizes 7 "if-then" rules extracted by tracing a path from the root node to each leaf node.

\section{Discussion}

The aim of the present study was to provide reliable evidence about the effects of various factors on the risk of CIMT among patients with T2DM in Western China. Unlike most previous studies, in addition to a traditional statistical analysis, we simultaneously employed a decision tree analysis to make our results more reliable.

\section{The effects of traditional risk factors on CIMT in patients with T2DM}

Age, sex, and smoking are well-known traditional risk factors affecting CIMT [16-20]. Our results were basically consistent with those of previous studies. Univariate analyses showed that there were significant differences in sex, age, and smoking status between the CIMT (+) group and the control group. Correspondingly, both the logistic regression and decision tree models showed that smoking was the most crucial risk factor for CIMT in patients with T2DM. Interestingly, several previous studies have shown that in a nondiabetic population, the mean value of CIMT was higher in men than in women $[43,44]$. However, a study from Taiwan [18] investigated the factors determining sex differences in CIMT in different age groups. The results showed that although the mean value of CIMT was higher in men than in women, the rapid increase in cardiovascular risk factors in women after 55 years was a vital cause of CIMT thickening in this age group. In the present study, logistic regression showed that being female was a risk factor for CIMT thickening associated with T2DM, which should be considered in the context of the following possible factors: first, the special nature of the study population. The subjects in our study were limited to patients with T2DM, rather than a healthy checkup population. Second, menopause is an undisputed important risk factor for both CVD [45-48] and T2DM [49-51]. The mean age at which Chinese women undergo menopause is generally between 45 and 50 years old [52, 53], and we recruited a total of 529 women with T2DM, of whom more than $80 \%$ were over 45 years old, which meant that the vast majority of female patients were in menopausal or postmenopausal states. The subsequent decision tree analysis also showed that nonsmoking women with VFA $\geq 80 \mathrm{~cm}^{2}$ had an increased probability of CIMT thickening. Therefore, it would be beneficial to increase the sample size in different age groups in the future to verify the possible influence of the interactions among sex, age and other factors.

We also explored the effect of lipids on CIMT in patients with T2DM. The results showed that the HDL-c level in the CIMT (+) group was significantly 
Table 3 Variable assignment used in logistic regression and decision tree

\begin{tabular}{|c|c|}
\hline Variable & Assignment \\
\hline \multirow[t]{3}{*}{ CIMT } & L-CIMT or R-CIMT met any of the following criteria \\
\hline & $0=$ normal $(\mathrm{CIMT}<1 \mathrm{~mm})$ \\
\hline & $1=$ increased CIMT (CIMT $\geq 1 \mathrm{~mm})$ \\
\hline \multirow[t]{2}{*}{ Gender } & $0=$ male \\
\hline & $1=$ female \\
\hline \multirow[t]{2}{*}{ Age } & $1=$ young and middle-aged (age $<60$ years) \\
\hline & $2=$ old age (age $\geq 60$ years) \\
\hline \multirow[t]{2}{*}{ Smoking } & $0=$ no \\
\hline & $1=$ yes \\
\hline \multirow[t]{2}{*}{ Blood pressure } & $0=$ normal $(\mathrm{SBP}<140 \mathrm{mmHg}$ and/or DBP $<90 \mathrm{mmHg})$ \\
\hline & $1=$ hypertention $(\mathrm{SBP} \geq 140 \mathrm{mmHg}$ and/or $\mathrm{DBP} \geq 90 \mathrm{mmHg}$ ) \\
\hline \multirow[t]{4}{*}{ BMI } & $1=$ normal $\left(\mathrm{BMl}<24 \mathrm{~kg} / \mathrm{m}^{2}\right)$ \\
\hline & $2=$ overweight $\left(24 \mathrm{~kg} / \mathrm{m}^{2} \leq \mathrm{BMl}<28 \mathrm{~kg} / \mathrm{m}^{2}\right)$ \\
\hline & $3=$ obesity $\left(28 \mathrm{~kg} / \mathrm{m}^{2} \leq \mathrm{BMl}<30 \mathrm{~kg} / \mathrm{m}^{2}\right)$ \\
\hline & $4=$ severe obesity $\left(\mathrm{BMI} \geq 30 \mathrm{~kg} / \mathrm{m}^{2}\right)$ \\
\hline \multirow[t]{2}{*}{ Waist circumference } & $0=$ normal $($ male $<90 \mathrm{~cm}$, female $<85 \mathrm{~cm})$ \\
\hline & $1=$ increased waist circumference (male $\geq 90 \mathrm{~cm}$, female $\geq 85 \mathrm{~cm}$ ) \\
\hline \multirow[t]{2}{*}{ VFA } & $0=$ normal $\left(V F A<80 \mathrm{~cm}^{2}\right)$ \\
\hline & $1=$ increased VFA $\left(\right.$ VFA $\left.\geq 80 \mathrm{~cm}^{2}\right)$ \\
\hline \multirow[t]{2}{*}{ SFA } & $0=$ normal $\left(S F A<100 \mathrm{~cm}^{2}\right)$ \\
\hline & $1=$ increased SFA $\left(S F A \geq 100 \mathrm{~cm}^{2}\right)$ \\
\hline \multirow[t]{3}{*}{ Glu 0} & $1=$ excessively controlled $(\mathrm{Glu} 0<4.4 \mathrm{mmol} / \mathrm{L})$ \\
\hline & $2=$ well controlled $(4.4 \mathrm{mmol} / \mathrm{L} \leq \mathrm{Glu} 0 \leq 7.0 \mathrm{mmol} / \mathrm{L})$ \\
\hline & $3=$ poorly controlled $(\mathrm{Glu} 0>7.0 \mathrm{mmol} / \mathrm{L})$ \\
\hline \multirow[t]{3}{*}{ Glu120 } & $1=$ well controlled (Glu120 $\leq 7.8 \mathrm{mmol} / \mathrm{L})$ \\
\hline & $2=$ generally controlled $(7.8 \mathrm{mmol} / \mathrm{L}<\mathrm{Glu} 120<10 \mathrm{mmol} / \mathrm{L})$ \\
\hline & $3=$ poorly controlled (Glu120 $\geq 10 \mathrm{mmol} / \mathrm{L})$ \\
\hline $\mathrm{HbA1c}$ & $\begin{array}{l}1=\text { well controlled }(\mathrm{HbA} 1 \mathrm{c}<7 \%) \\
2=\text { generally controlled }(7 \% \leq \mathrm{HbA} 1 \mathrm{c}<8 \%) \\
3=\text { poorly controlled }(\mathrm{HbA} 1 \mathrm{c} \geq 8 \%)\end{array}$ \\
\hline \multirow[t]{3}{*}{ CKD } & $1=\mathrm{G} 1(\mathrm{eGFR} \geq 90 \mathrm{ml} / \mathrm{min})$ \\
\hline & $2=\mathrm{G} 2(60 \mathrm{ml} / \mathrm{min} \leq \mathrm{eGFR}<90 \mathrm{ml} / \mathrm{min})$ \\
\hline & $3=\mathrm{G} 3(30 \mathrm{ml} / \mathrm{min} \leq \mathrm{eGFR}<60 \mathrm{ml} / \mathrm{min})$ \\
\hline \multirow[t]{2}{*}{ UA } & $0=$ normal \\
\hline & $1=$ hyperuricemia (male $>420$ ummol/L; female $>360$ umol/L) \\
\hline \multirow[t]{2}{*}{ Blood lipid } & $0=$ normal \\
\hline & $\begin{array}{l}1 \text { = dyslipidaemia (met any of the following criteria: TG } \geq 2.26 \\
\mathrm{mmol} / \mathrm{L} ; \mathrm{TC} \geq 6.26 \mathrm{mmol} / \mathrm{L} ; \mathrm{LDL} \geq 4.14 \mathrm{mmol} / \mathrm{L} ; \mathrm{HDL}<1.04 \\
\mathrm{mmol} / \mathrm{L} \text { ) }\end{array}$ \\
\hline \multirow[t]{2}{*}{$A B I$} & $0=$ non-stenosis $(L-A B \mid$ and/or $R-A B I>0.9)$ \\
\hline & $1=$ stenosis $(\mathrm{L}-\mathrm{ABI}$ or $\mathrm{R}-\mathrm{ABI} \leq 0.9)$ \\
\hline
\end{tabular}

CIMT carotid intima media thickness, SBP systolic blood pressure, DBP diastolic blood pressure, $B M I$ body mass index, VFA visceral fat area, SFA subcutaneous fat area, Glu0 fasting blood glucose, Glu120 2-hour postprandial blood glucose, HbA1C glycated hemoglobin A1c, CKD chronic kidney disease, eGFR estimated glomerular filtration rate, $U A$ uric acid, $T G$ triglyceride, $T C$ cholesterol, $L D L-c$ low density lipoprotein cholesterol, $H D L$ - $c$ high density lipoprotein cholesterol, $A B I$ ankle brachial index, $L-A B$ l left ankle brachial index, $R$ - $A B$ I right ankle brachial index

lower than that in the CIMT $(-)$ group $(p<0.01)$, while other blood lipid indicators, including TG, TC, and LDL-c, were not different between the two groups $(p=0.436, p=0.166, p=0.497$, respectively). In addition, several studies have shown that blood pressure
[21], blood glucose level [25], blood glucose level fluctuation and C-peptide level [26, 27] were associated with CIMT thickening. In this study, SBP, DBP and C120 were higher in the CIMT $(+)$ group than in the control group (all $p<0.01$ ), but there was no significant 
Table 4 Logistic regression analysis of associated risk fators of CIMT in patients with T2DM

\begin{tabular}{lllllll}
\hline Variable & B & S.E, & Wals & $\boldsymbol{p}$ & OR & 95\% C.I. \\
\hline Gender & 0.806 & 0.209 & 14.852 & 0.000 & 2.239 & $1.486-3.373$ \\
Smoking & 1.751 & 0.201 & 75.846 & 0.000 & 5.759 & $3.884-8.541$ \\
BMI & 0.171 & 0.079 & 4.724 & 0.030 & 1.186 & $1.017-1.384$ \\
VFA & 0.311 & 0.149 & 4.333 & 0.037 & 1.364 & $1.018-1.828$ \\
Constant & -2.508 & 0.233 & 115.636 & 0.000 & 0.081 & \\
\hline
\end{tabular}

$B M /$ body mass index, VFA visceral fat area

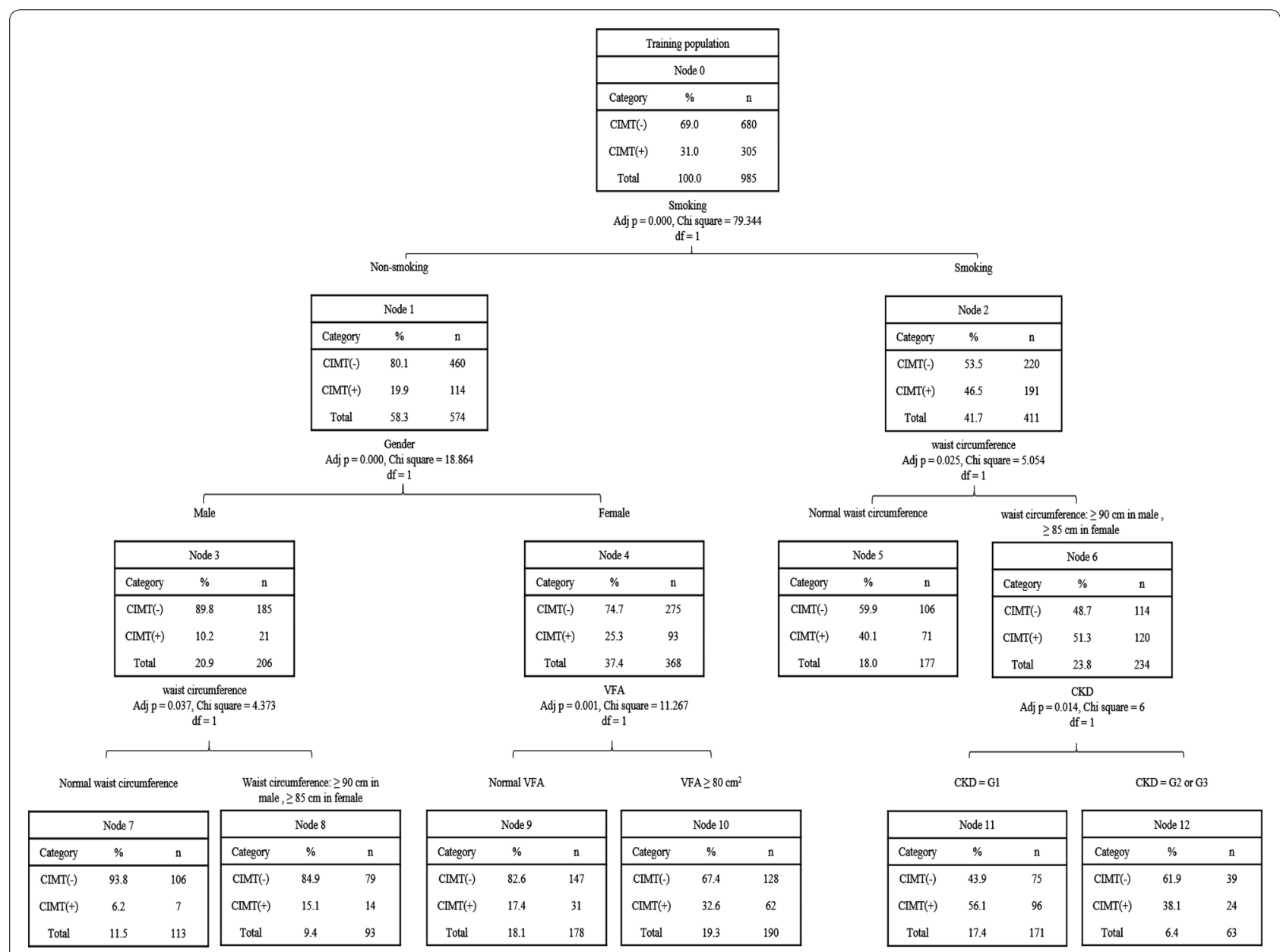

Fig. 2 Training dataset of decision tree model. R rule CIMT carotid intima media thickness, VFA visceral fat area, CKD chronic kidney disease

difference in Glu0, Glu120, C0 and HbA1c between the two groups (all $p>0.05$ ). It is worth noting that both the logistic regression model and the decision tree model ultimately excluded the relevant indicators blood glucose, blood lipids and blood pressure from the model. These discrepancies between our study and previous studies might have arisen from the following factors: first, compared with other studies, we chose CIMT $\geq 1.0 \mathrm{~mm}$ as the threshold for CIMT thickening [35], which was stricter and more in line with the characteristics of the Chinese population; moreover, the design, study population, and exclusion criteria among the studies were distinct; last, the use of antidiabetic, antihypertensive and lipid-lowering drugs may have influenced the results of the study to some extent. 
Table 5 Rules extracted from decision tree

\begin{tabular}{|c|c|c|}
\hline Rule & If & Then \\
\hline R1 & If: non-smoking, male and normal waist circumference & Then class: patients with normal CIMT (93.8\%) \\
\hline $\mathrm{R} 2$ & If: non-smoking, male and waist circumference $\geq 90 \mathrm{~cm}$ & Then class: patients with increased CIMT (15.1\%) \\
\hline R3 & If: non-smoking, female and normal VFA & Then class: patints with normal CIMT (82.6\%) \\
\hline R4 & If: non-smoking, female and VFA $\geq 80 \mathrm{~cm}^{2}$ & Then class: patints with increased CIMT (32.6\%) \\
\hline R5 & If: smoking, normal waist circumference & Then class: patients with normal CIMT (59.9\%) \\
\hline R6 & $\begin{array}{l}\text { If: smoking, waist circumference } \geq 90 \mathrm{~cm} \text { in male or } \geq 85 \mathrm{~cm} \text { in female and CKD }=\mathrm{G} 1 \text { (eGFR } \\
\quad \geq 90 \mathrm{ml} / \mathrm{min} \text { ) }\end{array}$ & Then class: patients with increased CIMT (56.1\%) \\
\hline R7 & $\begin{array}{l}\text { If: smoking, waist circumference } \geq 90 \mathrm{~cm} \text { in male or } \geq 85 \mathrm{~cm} \text { in female and CKD = G2 or G3 } \\
\quad(30 \mathrm{ml} / \mathrm{min} \leq \mathrm{eGFR}<90 \mathrm{ml} / \mathrm{min})\end{array}$ & Then class: patients with normal CIMT (61.9\%) \\
\hline
\end{tabular}

$R$ rule, CIMT carotid intima media thickness, VFA visceral fat area, CKD chronic kidney disease

\section{Effect of VFA on CIMT in patients with T2DM}

In recent years, the global prevalence of obesity has markedly increased, and the incidence of obesity-related T2DM has increased annually [54]. Unlike in Caucasian individuals, body fat in Chinese individuals tends to accumulate in the abdominal cavity, which is more likely to result in abdominal obesity. A study based on the Chinese population showed that abdominal obesity is currently an increasing trend in China, with an adult prevalence rate of $29.1 \%$ (28.6\% for men and $29.6 \%$ for women) [55]. More importantly, the prevalence rates of T2DM in the overweight and obese population in China are $12.8 \%$ and $18.5 \%$, respectively [56]. Therefore, it is very important to explore the internal relationships among fat metabolism, T2DM and vascular complications.

Increasing evidence has shown that visceral fat is a risk factor for T2DM, atherosclerosis and cardiovascular and cerebrovascular diseases [28,57]. There are also racial and geographical differences with regard to the definition of VFA thresholds. VFA $\geq 100 \mathrm{~cm}^{2}$ is generally accepted as increased visceral fat in Europe, the United States and Japan [58, 59]. Geographically and ethnically, although China and Japan are very similar, VFA $\geq 80 \mathrm{~cm}^{2}$ is recommended as the optimal threshold for evaluating abdominal obesity patients with T2DM in the Chinese population [36, 60]. Therefore, in this study, VFA $\geq 80 \mathrm{~cm}^{2}$ was used as the standard to evaluate the increase in visceral fat. The VFA measurement method in our study was bioelectrical impedance, which has a good correlation with CT [61]. Previous studies have illustrated that VFA is a crucial risk factor for CIMT thickening in middle-aged and elderly Chinese populations [60, 62]. Univariate analyses in the present study showed that in patients with T2DM, VFA was higher in the CIMT $(+)$ group than in the CIMT $(-)$ group $(p<0.01)$. Furthermore, both the logistic regression analysis and decision tree model emphasized that VFA was a risk factor for CIMT thickening in patients with T2DM.
The influence of traditional obesity-related factors on CIMT in patients with T2DM

With consideration of the metabolic characteristics of the Chinese population, we defined $\mathrm{BMI} \geq 24 \mathrm{~kg} / \mathrm{m}^{2}$ as overweight and BMI $\geq 28 \mathrm{~kg} / \mathrm{m}^{2}$ as obesity; we defined waist circumference $\geq 90 \mathrm{~cm}$ in males and waist circumference $\geq 80 \mathrm{~cm}$ in females as abdominal obesity [63]. The univariate analyses showed that BMI, waist circumference, hip circumference and WHR were significantly higher in the CIMT $(+)$ group than in CIMT $(-)$ group (all $p<0.01$ ). The correlation between VFA and waist circumference was relatively stronger (Pearson correlation coefficient $r=0.787$ ) than the correlation between VFA and BMI. However, it was noteworthy that, unlike VFA, neither BMI nor waist circumference was included in the logistic regression analysis and decision tree at the same time. On the one hand, BMI cannot accurately measure the change in abdominal fat distribution among individuals [64] and the guidelines from the ACC/AHA on the assessment of cardiovascular risk [65] does not consider BMI to be a predictor of cardiovascular risk. In addition, a small group of people in the obese or overweight population never have CVD, leading to the proposed concept of "metabolically healthy obesity" (MHO), which is closely associated with younger age, more aerobic exercise, comprehensive and balanced nutritional status and less VFA [66]. Likewise, although a reduction in waist circumference is always associated with a reduction in visceral adipose tissue (VAT), waist circumference does not precisely reflect changes in VFA [28].

Previous research from Wang et al. [60] found that CIMT increased as VFA increased in both the $\mathrm{BMI}<25 \mathrm{~kg} / \mathrm{m}^{2}$ group and the $\mathrm{BMI} \geq 25 \mathrm{~kg} / \mathrm{m}^{2}$ group in non-T2DM Chinese participants. Other studies based on Japanese T2DM populations have shown that subjects with normal BMI and increased VFA $\left(\mathrm{BMI}<25 \mathrm{~kg} / \mathrm{m}^{2}\right.$ and $\mathrm{VFA} \geq 100 \mathrm{~cm}^{2}$ group) were more 
likely to suffer from systemic arteriosclerosis [67] and arterial stiffness [68].

In our study, a similar subgroup analysis was conducted. Taking into account the metabolic characteristics of the Chinese population, the subjects in our study were divided into four subgroups according to VFA and BMI: VFA $<80 \mathrm{~cm}^{2}$ and BMI $<24 \mathrm{~kg} / \mathrm{m}^{2}$ [VFA (-) BMI (-) group, $\mathrm{n}=386], \mathrm{VFA}<80 \mathrm{~cm}^{2}$ and $\mathrm{BMI} \geq 24 \mathrm{~kg} /$ $\mathrm{m}^{2}$ [VFA (-) BMI (+) group, $\mathrm{n}=230$ ], VFA $\geq 80 \mathrm{~cm}^{2}$ and $\mathrm{BMI}<24 \mathrm{~kg} / \mathrm{m}^{2}$ [VFA $(+)$ BMI $(-)$ group, $\left.\mathrm{n}=104\right]$ ], and $\mathrm{VFA} \geq 80 \mathrm{~cm}^{2}$ and $\mathrm{BMI} \geq 24 \mathrm{~kg} / \mathrm{m}^{2}$ [VFA $(+)$ BMI $(+)$ group, $n=652]$. However, there were no significant differences in CIMT among the four groups (all $p>0.05$ ). These results are illustrated in the Additional file 1. Differences in the exclusion criteria and VFA threshold values may be the reason for the divergence between the results of this study and other studies.

In addition to BMI and waist circumference, SFA is also an indicator that can be used to evaluate body fat distribution. Visceral and ectopic fats are deposited when the subcutaneous adipose tissue (SAT) cannot expand to accommodate excessive energy intake [69]. Nevertheless, SFA and VFA have different anatomical and functional significance $[69,70]$. The results of previous studies regarding the relationship between SFA and CVD are controversial [71-73]. Some studies have suggested that increased SFA was positively associated with CVD, while some studies have suggested that moderately increased SFA is beneficial for the balance of blood glucose and blood lipids, thereby exerting protective effects on cardiovascular health.

Although the SFA in the CIMT (+) group was significantly greater than that in the CIMT (-) group in this study, and the correlation analysis between VFA and SFA showed that the Pearson correlation coefficient $r$ was 0.762 , the logistic regression and decision tree models excluded SFA from the model. A study from Japan showed that increased VFA $\left(\geq 100 \mathrm{~cm}^{2}\right)$ and low SFA $\left(\leq 100 \mathrm{~cm}^{2}\right)$ were the determinants of atherosclerosis in T2DM patients [37]. Unfortunately, only 5 patients from the total sample of subjects in our study had the characteristics of SFA $<100 \mathrm{~cm}^{2}$ and VFA $\geq 80 \mathrm{~cm}^{2}$, so a valuable subgroup analysis could not be performed. It is necessary to expand the sample size of this subgroup in the future.

\section{Decision tree analysis of factors influencing CIMT in patients with T2DM}

Although traditional statistical methods such as logistic regression can identify statistically significant risk factors, it is impossible to make qualitative judgments about the likelihood that each risk factor will be at specific levels. A decision tree is an effective machine learning method used to classify data based on a series of rules
[74]. It has a "flowchart-like" structure that can extract classification rules from a set of irregular cases, compare the attribute values in each internal node, judge the branches below the node, and obtain the classification conclusion in the leaf nodes. In other words, the paths from root to leaf represent classification rules. Recently, the application of decision trees has become increasingly extensive in the field of medical research $[74,75]$. Therefore, to make our results more convincing and robust, we further carried out a decision tree analysis based on the "CHAID" method, which has become one of the most common decision tree algorithms. Until now, no research has employed a decision tree to analyze the effect of associated factors on CIMT in patients with T2DM.

As described in Fig. 2, the variables that finally remained in the model included smoking, sex, waist circumference, VFA and CKD. The "if-then" rules summarized in Table 5 were the "details" that were extracted from the decision tree. Specifically, smoking was the most crucial risk factor affecting CIMT in patients with T2DM; among nonsmokers, females were at relatively higher risk for increased CIMT, especially those an increased VFA (VFA $\geq 80 \mathrm{~cm}^{2}$ ). For smokers, an increase in waist circumference (male $\geq 90 \mathrm{~cm}$ and female $\geq 85 \mathrm{~cm}$ ) was a risk factor for increased CIMT, especially in patients with CKD 1 and 2. More importantly, we found that smoking, sex and VFA were essential factors influencing CIMT in patients with T2DM, which was basically consistent with the results of the logistic regression analysis.

\section{Limitations}

In brief, this study was the first to analyze the factors influencing CIMT in patients with T2DM in Western China. However, it should be noted that there were several limitations. First, the present study did not record the use of antidiabetic, lipid-lowering and antihypertensive medications in patients, so it is impossible to exclude the possibility of an influence of these medications. Moreover, we should note that the duration of diabetes mellitus was not available for analysis in this study. Therefore, these factors may have contributed to differences in research findings.

\section{Conclusions}

In the present study, the risk factors for CIMT thickening in patients with T2DM in Western China were explored for the first time. Despite some limitations, there were several valuable findings. First, traditional risk factors such as smoking and increased BMI had significant effects on increased CIMT associated with T2DM. Second, unlike other studies conducted in the population receiving regular health checkups, the data 
from this study supported female sex as a vital factor influencing CIMT in patients with T2DM. More importantly, our data emphasize the role of VFA in the management and evaluation of diabetic macroangiopathy in the future. Meanwhile, unlike traditional statistical methods, the decision tree model used in our study, with its simple, intuitive and practical hierarchical methods, could help clinicians make more effective risk-based decisions, which is worth promoting in future medical research. In the future, we will continue to expand the sample size, add new indicators to assess vascular disease, and further enrich and strengthen our theory in order to better prevent and manage diabetic vascular disease.

\section{Supplementary information}

Supplementary information accompanies this paper at https://doi. org/10.1186/s13098-020-0517-8.

Additional file 1. Results of sample size calculation.

Additional file 2. STROBE Statement-checklist of items that should be included in reports of cross-sectional studies.

Additional file 3. Characteristics of patients with type 2 daibetes in subgroups.

\section{Abbreviations}

CVD: cardiovascular disease; T2DM: type 2 diabetes; CIMT: carotid intima media thickness; VFA: visceral fat area; SBP: systolic blood pressure; DBP: diastolic blood pressure; BMI: body mass index; CKD: chronic kidney disease; IDF: International Diabetes Federation; MMC: Metabolic Disease Management Center; WHO: World Health Organization; GFR: glomerular filtration rate; WHR: waist-hip ratio; Glu0: fasting blood glucose; CO: fasting serum C peptide; InsO: fasting serum insulin; $\mathrm{HbA} 1 \mathrm{c}$ : glycated hemoglobin A1c; TG: triglyceride; TC: cholesterol; HDL-c: high-density lipoprotein cholesterol; LDL-c: low-density lipoprotein cholesterol; Scr: serum creatine; BUN: blood urea nitrogen; UA: uric acid; c-aMDRD: Chinese-abbreviated modification of diet in renal disease; OGTT: oral glucose tolerance test; Glu120: 2-h postprandial blood glucose; C120: 2-h postprandial serum C-peptide; Ins120: 2-h postprandial serum insulin; L-CIMT: left CIMT; R-CIMT: right CIMT; SFA: subcutaneous fat area; ABI: ankle brachial index; L-ABI: left ABI; R-ABI: right ABI; KDIGO: Kidney Disease Improving Global Outcomes; G: GFR category; HUA: hyperuricemia; SD: standard deviation; CHAID: Chi squared automatic interaction detector; SPSS: Statistical Package for Social Sciences.

\section{Acknowledgements}

Not applicable.

\section{Authors' contributions}

YYZ wrote the article and edited the manuscript; $Y Y$ was responsible for revising the manuscript for important intellectual content and final approval of the version of the article to be published; HMQ revised the manuscript; $Y Y Z$ and YYH were responsible for the statistical analysis. All authors read and approved the final manuscript.

\section{Funding}

This study was supported by the Endocrine Clinical Medical Center of Yunnan Province, No. ZX2019-02-02; the Natural Science Foundation of China (No. 81760734; No. 31660313); the Natural Science Foundation of Yunnan Province (No. 2017FA048; No. 2017FE467); the fund of the Diabetic Innovation Team (No. 2019HC002); and the fund for medical leaders in Yunnan Province (No. L-201609).

\section{Availability of data and materials}

The datasets used in the present study are available from the corresponding author on reasonable request.

\section{Ethics approval and consent to participate}

This study was conducted in line with the principles set out in the Helsinki Declaration and was approved by the Ethics Committee of the Sixth Affiliated Hospital of Kunming Medical University (No. 201934).

\section{Consent for publication}

Not applicable.

\section{Competing interests}

The authors declare that they have no competing interests.

\section{Author details}

${ }^{1}$ Department of Endocrinology and Metabolism, Fourth Affiliated Hospital of Kunming Medical University, The Second People's Hospital of Yunnan Province, Kunming 650021, China. ${ }^{2}$ Department of Endocrinology and Metabolism, Sixth Affiliated Hospital of Kunming Medical University, The People's Hospital of Yuxi City, Yuxi 653100, China. ${ }^{3}$ Center of Tree Shrew Germplasm Resources, Institute of Medical Biology, Chinese Academy of Medical Sciences and Peking Union Medical College, Kunming 650021, China.

Received: 2 December 2019 Accepted: 10 January 2020

Published online: 28 January 2020

\section{References}

1. Whiting DR, Guariguata L, Weil C, Shaw J. IDF diabetes atlas: global estimates of the prevalence of diabetes for 2011 and 2030. Diabetes Res Clin Pract. 2011;94:311-21.

2. Sarwar N, Gao P, Seshasai SR, Gobin R, Kaptoge S, Di Angelantonio E, et al. Diabetes mellitus, fasting blood glucose concentration, and risk of vascular disease: a collaborative meta-analysis of 102 prospective studies. Lancet. 2010;375:2215-22.

3. Huxley R, Barzi F, Woodward M. Excess risk of fatal coronary heart disease associated with diabetes in men and women: meta-analysis of 37 prospective cohort studies. BMJ. 2006;332:73-8.

4. Bivona G, Agnello L, Bellia C, Lo Sasso B, Ciaccio M. Diagnostic and prognostic value of H-FABP in acute coronary syndrome: still evidence to bring. Clin Biochem. 2018;58:1-4.

5. Agnello L, Bivona G, Lo Sasso B, Scazzone C, Bazan V, Bellia C, et al. Galectin-3 in acute coronary syndrome. Clin Biochem. 2017;50:797-803.

6. Agnello L, Bivona G, Novo G, Scazzone C, Muratore R, Levantino P, et al. Heart-type fatty acid binding protein is a sensitive biomarker for early AMl detection in troponin negative patients: a pilot study. Scand J Clin Lab Invest. 2017;77:428-32.

7. Frostegard J. Immunity, atherosclerosis and cardiovascular disease. BMC Med. 2013:11:117.

8. Lorenz MW, Markus HS, Bots ML, Rosvall M, Sitzer M. Prediction of clinical cardiovascular events with carotid intima-media thickness: a systematic review and meta-analysis. Circulation. 2007;115:459-67.

9. Novo S, Peritore A, Trovato RL, Guarneri FP, Di Lisi D, Muratori I, et al. Preclinical atherosclerosis and metabolic syndrome increase cardio- and cerebrovascular events rate: a 20-year follow up. Cardiovasc Diabetol. 2013;12:155.

10. Greenland P, Alpert JS, Beller GA, Benjamin EJ, Budoff MJ, Fayad ZA, et al. 2010 ACCF/AHA guideline for assessment of cardiovascular risk in asymptomatic adults: a report of the American College of Cardiology Foundation/American Heart Association Task Force on Practice Guidelines. J Am Coll Cardiol. 2010;56:e50-103.

11. Mancia G, Fagard R, Narkiewicz K, Redon J, Zanchetti A, Bohm M, et al. 2013 ESH/ESC practice guidelines for the management of arterial hypertension. Blood Press. 2014;23:3-16.

12. Touboul PJ, Hennerici MG, Meairs S, Adams H, Amarenco P, Bornstein N, et al. Mannheim carotid intima-media thickness and plaque consensus (2004-2006-2011). An update on behalf of the advisory board of the $3 \mathrm{rd}$, 4th and 5th watching the risk symposia, at the 13th, 15th and 
20th European Stroke Conferences, Mannheim, Germany, 2004, Brussels, Belgium, 2006, and Hamburg, Germany, 2011. Cerebrovasc Dis. 2012;34:290-6.

13. Goff DC Jr, Lloyd-Jones DM, Bennett G, Coady S, D'Agostino RB Sr, Gibbons R, et al. 2013 ACC/AHA guideline on the assessment of cardiovascular risk: a report of the American College of Cardiology/American Heart Association Task Force on Practice Guidelines. J Am Coll Cardiol. 2014;63:2935-59.

14. Naqvi TZ, Lee MS. Carotid intima-media thickness and plaque in cardiovascular risk assessment. JACC Cardiovasc Imaging. 2014;7:1025-38.

15. Oygarden H. Carotid intima-media thickness and prediction of cardiovascular disease. J Am Heart Assoc. 2017;6:e005313.

16. Touboul PJ, Vicaut E, Labreuche J, Acevedo M, Torres V, Ramirez-Martinez $J$, et al. Common carotid artery intima-media thickness: the Cardiovascular Risk Factor Multiple Evaluation in Latin America (CARMELA) study results. Cerebrovasc Dis. 2011:31:43-50.

17. van den Munckhof ICL, Jones H, Hopman MTE, de Graaf J, Nyakayiru J, van Dijk B, et al. Relation between age and carotid artery intima-medial thickness: a systematic review. Clin Cardiol. 2018;41:698-704.

18. Su TC, Chien KL, Jeng JS, Chen MF, Hsu HC, Torng PL, et al. Age- and gender-associated determinants of carotid intima-media thickness: a community-based study. J Atheroscler Thromb. 2012;19:872-80.

19. Jiang F, Wang J, Zhang R, Chen M, Peng D, Sun X, et al. Effects of active and passive smoking on the development of cardiovascular disease as assessed by a carotid intima-media thickness examination in patients with type 2 diabetes mellitus. Clin Exp Pharmacol Physiol. 2015:42:444-50

20. Hansen K, Ostling G, Persson M, Nilsson PM, Melander O, Engstrom G, et al. The effect of smoking on carotid intima-media thickness progression rate and rate of lumen diameter reduction. Eur J Intern Med. 2016:28:74-9.

21. Itoh H, Kaneko H, Kiriyama H, Yoshida Y, Nakanishi K, Mizuno Y, et al. Relation between the updated blood pressure classification according to the American College of Cardiology/American Heart Association Guidelines and Carotid Intima-Media Thickness. Am J Cardiol. 2019;124:396-401.

22. Boloukat RR, Ramezankhani A, Hasheminia M, Tasdighi E, Azizi F, Hadaegh F. Impact of blood pressure, cholesterol and glucose in the association between adiposity measures and coronary heart disease and stroke among Iranian population. Clin Nutr. 2018;37:2060-7.

23. Gao N, Zhang W, Zhang YZ, Yang Q, Chen SH. Carotid intima-media thickness in patients with subclinical hypothyroidism: a meta-analysis. Atherosclerosis. 2013:227:18-25.

24. Aziz M, Kandimalla Y, Machavarapu A, Saxena A, Das S, Younus A, et al. Effect of thyroxin treatment on carotid intima-media thickness (CIMT) reduction in patients with subclinical hypothyroidism $(\mathrm{SCH})$ : a metaanalysis of clinical trials. J Atheroscler Thromb. 2017;24:643-59.

25. Einarson TR, Hunchuck J, Hemels M. Relationship between blood glucose and carotid intima media thickness: a meta-analysis. Cardiovasc Diabetol. 2010;9:37.

26. Cesana F, Giannattasio C, Nava S, Soriano F, Brambilla G, Baroni M, et al. Impact of blood glucose variability on carotid artery intima media thickness and distensibility in type 1 diabetes mellitus. Blood Press. 2013;22:355-61.

27. Liu M, Ao L, Hu X, Ma J, Bao K, Gu Y, et al. Influence of blood glucose fluctuation, C-peptide level and conventional risk factors on carotid artery intima-media thickness in Chinese Han patients with type 2 diabetes mellitus. Eur J Med Res. 2019;24:13.

28. Neeland IJ, Ross R, Despres JP, Matsuzawa Y, Yamashita S, Shai I, et al, Visceral and ectopic fat, atherosclerosis, and cardiometabolic disease: a position statement. Lancet Diabetes Endocrinol. 2019;7:715-25.

29. Classification and Diagnosis of Diabetes. Standards of Medical Care in Diabetes-2019. Diabetes Care. 2019:42:S13-28.

30. Guo M, Niu JY, Ye XW, Han XJ, Zha Y, Hong Y, et al. Evaluation of various equations for estimating renal function in elderly Chinese patients with type 2 diabetes mellitus. Clin Interv Aging. 2017;12:1661-72.

31. Ma YC, Zuo L, Chen JH, Luo Q, Yu XQ, Li Y, et al. Modified glomerular filtration rate estimating equation for Chinese patients with chronic kidney disease. J Am Soc Nephrol. 2006;17:2937-44

32. Liu X, Qiu X, Shi C, Huang H, Huang J, Li M, et al. Modified glomerular filtration rate-estimating equations developed in asiatic population for chinese patients with type 2 diabetes. Int J Endocrinol. 2014;2014:521071.
33. Joint Committee for Guideline Revision. 2018 Chinese guidelines for prevention and treatment of hypertension-a report of the revision committee of Chinese guidelines for prevention and treatment of hypertension. J Geriatr Cardiol. 2019;16:182-241.

34. Chinese Society of Endocrinology. Expert consensus on integrated management of type 2 diabetes and obesity in China. Chin J Endocrinol Metab. 2016;32:623-7.

35. Ultrasonic Physicians Branch of Chinese Medical Association. Guidelines for vascular ultrasonography. Chin J Ultrason. 2015:9:254-60.

36. Chinese Diabetes Society. Guidelines for the prevention and treatment of type 2 diabetes in China. Chin J Endocrinol Metab. 2014;10:893-942.

37. Bouchi R, Takeuchi T, Akihisa M, Ohara N, Nakano Y, Nishitani R, et al. High visceral fat with low subcutaneous fat accumulation as a determinant of atherosclerosis in patients with type 2 diabetes. Cardiovasc Diabetol. 2015;14:136.

38. Joint Committee for Developing Chinese guidelines on Prevention and Treatment of Dyslipidemia in Adults. Chinese guidelines on Prevention and Treatment of Dyslipidemia in Adults. Zhonghua Xin Xue Guan Bing Za Zhi. 2007;35:390-419.

39. Levey AS, Eckardt KU, Tsukamoto Y, Levin A, Coresh J, Rossert J, et al. Definition and classification of chronic kidney disease: a position statement from Kidney Disease: improving Global Outcomes (KDIGO). Kidney Int. 2005;67:2089-100.

40. Pou KM, Massaro JM, Hoffmann U, Vasan RS, Maurovich-Horvat P, Larson $M G$, et al. Visceral and subcutaneous adipose tissue volumes are crosssectionally related to markers of inflammation and oxidative stress: the Framingham Heart Study. Circulation. 2007:116:1234-41.

41. Multidisciplinary Expert Task Force on Hyperuricemia and Related Diseases. Chinese multidisciplinary expert consensus on the diagnosis and treatment of hyperuricemia and related diseases. Chin Med J (Engl). 2017:130:2473-88.

42. Hickey GL, Grant SW, Dunning J, Siepe M. Statistical primer: sample size and power calculations-why, when and how? Eur J Cardiothorac Surg. 2018;54:4-9.

43. Abd El-Hafez H, Elrakhawy MM, El-Baiomy AA, El-Eshmawy MM. Carotid intima media thickness is independently associated with male gender, middle age, and IGF-1 in metabolically healthy obese individuals. ISRN Obes. 2014;2014:545804.

44. Mazurek K, Zmijewski P, Czajkowska A, Lutoslawska G. Gender differences in carotid artery intima-media thickness and flow-mediated dilatation in young, physically active adults. J Sports Med Phys Fitness. 2014:54:298-306

45. Rosano GM, Vitale C, Marazzi G, Volterrani M. Menopause and cardiovascular disease: the evidence. Climacteric. 2007:10(Suppl 1):19-24.

46. Dosi R, Bhatt N, Shah P, Patell R. Cardiovascular disease and menopause. J Clin Diagn Res. 2014;8:62-4.

47. Lisabeth L, Bushnell C. Stroke risk in women: the role of menopause and hormone therapy. Lancet Neurol. 2012;11:82-91.

48. He L, Tang X, Li N, Wu YQ, Wang JW, Li JR, et al. Menopause with cardiovascular disease and its risk factors among rural Chinese women in Beijing: a population-based study. Maturitas. 2012;72:132-8.

49. Slopien R, Wender-Ozegowska E, Rogowicz-Frontczak A, Meczekalski B, Zozulinska-Ziolkiewicz D, Jaremek JD, et al. Menopause and diabetes: EMAS clinical guide. Maturitas. 2018;117:6-10.

50. Paschou SA, Anagnostis P, Pavlou DI, Vryonidou A, Goulis DG, Lambrinoudaki I. Diabetes in menopause: risks and management. Curr Vasc Pharmacol. 2019:17:556-63.

51. Zhou H, Zhang $\mathrm{C}, \mathrm{Ni}$ J, Han X. Prevalence of cardiovascular risk factors in non-menopausal and postmenopausal inpatients with type 2 diabetes mellitus in China. BMC Endocr Disord. 2019;19:98.

52. Huang W, Peng W, Wu Y, Huang X, Li C, Sun Z, et al. The status quo of perimenopausal and postmenopausal women in Chengdu: report of a population-based cross-sectional study. Sichuan Da Xue Xue Bao Yi Xue Ban. 2003;34:536-8.

53. Yang D, Haines CJ, Pan P, Zhang Q, Sun Y, Hong S, et al. Menopausal symptoms in mid-life women in southern China. Climacteric. 2008:11:329-36.

54. Lancet The. Obesity and diabetes in 2017: a new year. Lancet. 2017;389:1.

55. Zhang L, Wang Z, Wang X, Chen Z, Shao L, Tian Y, et al. Prevalence of abdominal obesity in China: results from a cross-sectional study of nearly half a million participants. Obesity (Silver Spring). 2019;27:1898-905. 
56. Yang SH, Dou KF, Song WJ. Prevalence of diabetes among men and women in China. N Engl J Med. 2010;362:2425-6 (author reply 6).

57. Lee JJ, Pedley A, Hoffmann U, Massaro JM, Levy D, Long MT. Visceral and intrahepatic fat are associated with cardiometabolic risk factors above other ectopic fat depots: the Framingham Heart Study. Am J Med. 2018;131(684-92):e12.

58. Despres JP, Lamarche B. Effects of diet and physical activity on adiposity and body fat distribution: implications for the prevention of cardiovascular disease. Nutr Res Rev. 1993;6:137-59.

59. Examination Committee of Criteria for 'Obesity Disease' in Japan, Japan Society for the Study of Obesity. New criteria for 'obesity disease' in Japan. Circ J. 2002;66:987-92.

60. Wang Y, Ma X, Zhou M, Zong W, Zhang L, Hao Y, et al. Contribution of visceral fat accumulation to carotid intima-media thickness in a Chinese population. Int J Obes (Lond). 2012;36:1203-8.

61. Omura-Ohata Y, Son C, Makino H, Koezuka R, Tochiya M, Tamanaha T, et al. Efficacy of visceral fat estimation by dual bioelectrical impedance analysis in detecting cardiovascular risk factors in patients with type 2 diabetes. Cardiovasc Diabetol. 2019;18:137.

62. Ren C, Zhang J, Xu Y, Xu B, Sun W, Sun J, et al. Association between carotid intima-media thickness and index of central fat distribution in middle-aged and elderly Chinese. Cardiovasc Diabetol. 2014;13:139.

63. Chinese Society of Endocrinology. Expert consensus on prevention and treatment of adult obesity in China. Chin J Endocrinol Metab. 2011;27:711-7.

64. Neeland IJ, Poirier P, Despres JP. Cardiovascular and metabolic heterogeneity of obesity: clinical challenges and implications for management. Circulation. 2018;137:1391-406.

65. Goff DC Jr, Lloyd-Jones DM, Bennett G, Coady S, D'Agostino RB, Gibbons R, et al. 2013 ACC/AHA guideline on the assessment of cardiovascular risk: a report of the American College of Cardiology/American Heart Association Task Force on Practice Guidelines. Circulation. 2014;129:S49-73.

66. Despres JP. Body fat distribution and risk of cardiovascular disease: an update. Circulation. 2012;126:1301-13.
67. Fukuda S, Hirata A, Nishizawa H, Nagao H, Kashine S, Kimura T, et al. Systemic arteriosclerosis and eating behavior in Japanese type 2 diabetic patients with visceral fat accumulation. Cardiovasc Diabetol. 2015;14:8.

68. Bouchi R, Minami I, Ohara N, Nakano Y, Nishitani R, Murakami M, et al. Impact of increased visceral adiposity with normal weight on the progression of arterial stiffness in Japanese patients with type 2 diabetes. BMJ Open Diabetes Res Care. 2015;3:e000081.

69. Cuthbertson DJ, Steele T, Wilding JP, Halford JC, Harrold JA, Hamer M, et al. What have human experimental overfeeding studies taught us about adipose tissue expansion and susceptibility to obesity and metabolic complications? Int J Obes (Lond). 2017;41:853-65.

70. Ibrahim MM. Subcutaneous and visceral adipose tissue: structural and functional differences. Obes Rev. 2010;11:11-8.

71. Abraham TM, Pedley A, Massaro JM, Hoffmann U, Fox CS. Association between visceral and subcutaneous adipose depots and incident cardiovascular disease risk factors. Circulation. 2015;132:1639-47.

72. Narumi H, Yoshida K, Hashimoto N, Umehara I, Funabashi N, Yoshida S, et al. Increased subcutaneous fat accumulation has a protective role against subclinical atherosclerosis in asymptomatic subjects undergoing general health screening. Int J Cardiol. 2009;135:150-5.

73. Han E, Lee YH, Lee BW, Kang ES, Lee IK, Cha BS. Anatomic fat depots and cardiovascular risk: a focus on the leg fat using nationwide surveys (KNHANES 2008-2011). Cardiovasc Diabetol. 2017;16:54.

74. Podgorelec V, Kokol P, Stiglic B, Rozman I. Decision trees: an overview and their use in medicine. J Med Syst. 2002;26:445-63.

75. Ramezankhani A, Hadavandi E, Pournik O, Shahrabi J, Azizi F, Hadaegh F. Decision tree-based modelling for identification of potential interactions between type 2 diabetes risk factors: a decade follow-up in a Middle East prospective cohort study. BMJ Open. 2016;6:e013336.

\section{Publisher's Note}

Springer Nature remains neutral with regard to jurisdictional claims in published maps and institutional affiliations.
Ready to submit your research? Choose BMC and benefit from:

- fast, convenient online submission

- thorough peer review by experienced researchers in your field

- rapid publication on acceptance

- support for research data, including large and complex data types

- gold Open Access which fosters wider collaboration and increased citations

- maximum visibility for your research: over $100 \mathrm{M}$ website views per year

At BMC, research is always in progress.

Learn more biomedcentral.com/submissions 